\title{
Review Article \\ The Role of Kenya Meteorological Service in Weather Early Warning in Kenya
}

\author{
Zablon W. Shilenje ${ }^{1}$ and Bob A. Ogwang ${ }^{2}$ \\ ${ }^{1}$ Kenya Meteorological Service, P.O. Box 30259, Nairobi 00100, Kenya \\ ${ }^{2}$ Nanjing University of Information Science and Technology, Nanjing 210044, China \\ Correspondence should be addressed to Zablon W. Shilenje; zablonweku@yahoo.com
}

Received 31 July 2014; Revised 2 February 2015; Accepted 10 February 2015

Academic Editor: Tido Semmler

Copyright (c) 2015 Z. W. Shilenje and B. A. Ogwang. This is an open access article distributed under the Creative Commons Attribution License, which permits unrestricted use, distribution, and reproduction in any medium, provided the original work is properly cited.

\begin{abstract}
Early warning in weather forecasting entails provision of timely and effective weather information that allows individuals, organisations, or communities exposed to likely weather hazards to take action that avoids or reduces their exposure to risks. Various sectors have developed different ways to mitigate the effects of climate anomalies. The study reviews the existing monitoring and response structures, and communications flow channels of weather data at different levels, focusing on the role of Kenya Meteorological Service (KMS). The methodology employed was literature review of various documents. The study argues that early warning and weather information communication are essential elements for effective governance of weather risks through a well-developed warning system. At the end, the study recommends strengthening the existing structures with respect to weather monitoring, processing, and dissemination of weather products to end users.
\end{abstract}

\section{Introduction}

Between 1980 and 2010, nearly 8500 natural disasters worldwide have taken the lives of nearly 2 million people and produced economic losses of over 1.2 trillion US dollars [1]. Recent statistics from the Centre for Research on the Epidemiology of Disasters (CRED) reveal that, of this total, some 90 per cent of the natural disasters, 70 per cent of casualties, and 75 per cent of economic losses were caused by weather, climate, or water related hazards. Such hazards include droughts, floods, windstorms, tropical cyclones and storm surges, extreme temperatures, landslides, wild fires or health epidemics, and insect infestations directly linked to the meteorological and hydrological conditions [2].

All these have not spared Kenya; for example, localized flooding, droughts, and lightning strikes are observed in parts of the country almost every year [3]. These extreme weather events in the country are often associated with very severe socioeconomic impacts that include lack of food, water, energy, and many other basic needs including destruction of infrastructure as well as loss of lives [4]. Such impacts have tended to retard socioeconomic growth of the country with the ultimate enhancement of poverty [5]. Currently, majority of the rural communities live under dire poverty since agriculture on which they depend for their livelihood has become more and more sensitive to severe and extreme weather events.

Monitoring, prediction, and timely early warning of the aforementioned extreme events are therefore the best strategies for mitigating their negative impacts on humanity and property [6]. This therefore calls for the existence of an effective and efficient early weather warning system. By definition, early warning provides timely weather information that allows individuals, organisations, or communities exposed to likely hazards take action that avoids or reduces their exposure to risks $[2,4,7]$. An early warning system therefore involves data collection, information development, modes of dissemination, and action triggering mechanisms.

In this paper, we review existing weather related early warning in the country within the Kenya Meteorological Service, with a view to establishing their status and effectiveness in operation. 


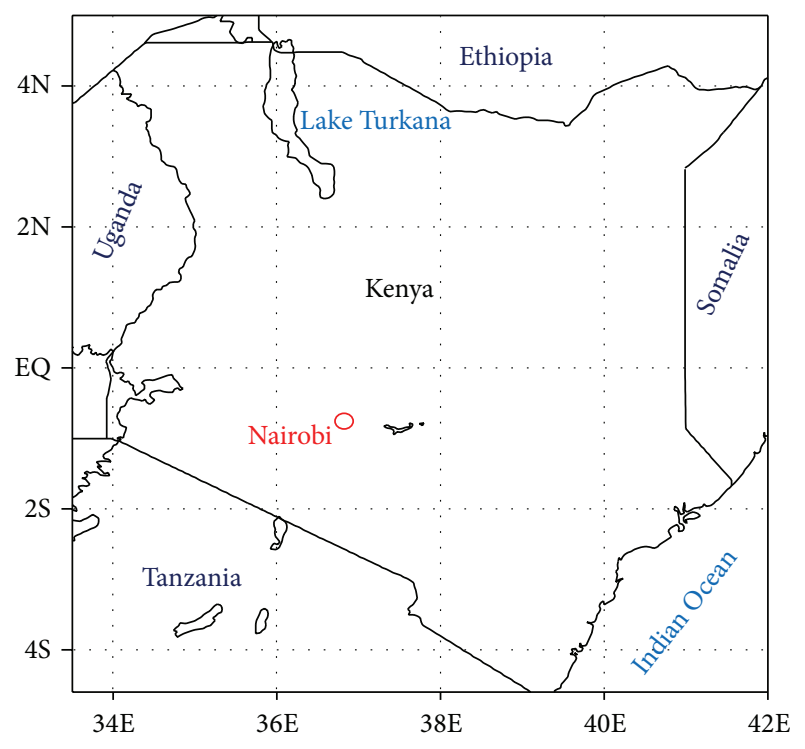

Figure 1: Map of Kenya showing area of study.

\section{Scope of Study}

The study covers service offered by Kenya Meteorological Service (KMS) in relation to early warning for Kenya given that there is no season in a year that the whole country receives normal rainfall devoid of extreme weather anomalies such as floods and droughts [8].

Kenya is one of the few countries in the world that sits astride the great latitude, the equator. The equator divides the country into almost two equal parts. The country is located approximately between latitudes $5^{\circ} \mathrm{N}$ and $4^{\circ} 40^{\prime} \mathrm{S}$ and extends from longitude $33^{\circ} 53^{\prime} \mathrm{E}$ to $41^{\circ} 55^{\prime} \mathrm{E}$ (Figure 1) covering a total area of $582686 \mathrm{Km}^{2}$. Although the country is a united republic, it is sectioned into 47 counties, administrative units created by the Kenya Constitution, 2010 [9].

Only a small region plays a crucial role in agricultural production, mainly rain-fed agriculture. The Intertropical Convergence Zone (ITCZ) dictates the distribution and spread of the rain regime creating two distinct wet seasons annually in Kenya and neighbouring countries [10]. The seasons are characterized as "long" rain season, occurring in March-AprilMay (MAM), and "short" rains, occurring in the months of October-November-December (OND). The rains coincide with the movement of the ITCZ northwards for NH summer and southwards for SH summer, respectively [11].

The main objective of this review is to identify and assess the role KMS plays in weather related early warning systems in Kenya.

\section{Methodological Approach}

This was principally a literature review on early warning in the KMS. It is worthwhile noting that the KMS has four branches whose mandates and responsibilities cover various aspects of operational work and research in applied meteorology. Some of these branches were identified as being important in sourcing the information required. These branches are forecasting and regional meteorological services, meteorological applications, technical services, and education training and research. Project reports and other publications were sought specializing in literature on early weather warning and research, as well as by visiting the sites of networks and organizations with speciality in this area. It is an accepted operation technique in applied science research to use documentary reviews [12] as a method of data analysis. The major documents reviewed included $[5,6,13]$. Some of the papers reviewed used different methods in their research such as questionnaires, surveys, interviews, and workshops data analysis.

\section{Review}

The socioeconomic wellbeing of the Kenyan communities is very sensitive to severe weather and extreme climate events. The country often experiences loss of life and destruction of property because of severe weather events such as floods and landslides, wind gusts, lightning, and prolonged droughts [3]. A large percentage of the rural communities within the country live below the poverty line since rain-fed agriculture, on which they rely for their livelihood has become more and more sensitive to severe weather that is now prevalent. Skilful and timely weather forecasts can help the government and communities mitigate the negative impacts of severe weather events through proper planning [14]. This is the essence of an effective early warning system $[2,7]$. The basic idea behind early warning is that the earlier and more accurately we are able to predict the likelihood of occurrence of natural and human induced hazards, the more likely we will be able to manage and mitigate a disaster's impact on society, economies, and environment [4]. The warning lead-time should be sufficient to allow appropriate measures to be put in place.

Despite the existence of wide knowledge on the hazards that cause disasters among the Kenyan communities, disasters have continued to cause destruction, sometimes, leading to loss of lives in many communities. Year after year, the frequency and severity of such disaster have continued to rise [14-16]. Whenever disasters associated with the weather occur, they often lead to massive destruction of property, displacement of populations, disruption of socioeconomic activities, migration, deaths, and many other miseries [17].

The effectiveness of the early warning largely depends on the organizations and mechanisms that control the response [4]. The players could be the government or NGOs, although often it could be a combination of both. Where there could be mistrust or suspicion between the two entities, then each works differently, creating duplicity in some cases [11]. Kenya, a diverse country in its climate and weather, needs both approaches in designing the program. The long-term desertification, expected higher temperatures [8], loss of land under rain-fed agriculture, rising population, and uncertainty in the economic development motivate the need for an all-around approach [13]. In the short term, drought and flood cycles, 
too little water or too much water, cause crop failure leading to unsustainable food supply and security [3].

Accurate warnings will have no impact if the population is not prepared or if alerts are received and not disseminated by the agencies receiving the messages. This review considers that the monitoring, analysis, and dissemination of weather information to the stakeholders by KMS are crucial in early warning [18]. The study assumes that dissemination of weather information is the starting point in constructing climate resilient societies in Kenya, a huge assumption but by no means unrealistic [19].

\section{Results and Discussion}

The review noted that there were a number of sectoral early warning systems operating in the country [3]. The study concentrated on the active role KMS plays in providing weather related information as part of its core function. KMS provides early warning information for the utilization in virtually all sectors of economy which are sensitive to weather anomalies using the most current state-of-the-art technology. Such a system was found to exist in many National Meteorological and Hydrological Centres with a well-documented case analyzed by Tarhule et al. [6] and Tarhule and Lamb [18]. The system comprises weather data observational network, telecommunications system (for fast exchange of data and products), data processing facilities for product generation, and data archival and information dissemination system.

Weather monitoring in the tropical countries, where small-scale systems dominate weather phenomena, requires a dense station network [20]. KMS operates 39 stations manned by well-trained personnel. The department also operates, on a voluntary basis, 600 rainfall stations. The rainfall stations had grown up to 2,000 but a number of stations have since then closed down due to lack of financial resources for regular inspections and repairs. To be able to effectively monitor weather over the country, KMS has data collection stations shown in Table 1, while Figure 2 shows a pictorial depiction of the observational network.

In the process of providing services in various sectors of the economy, KMS requires very fast computational power, fast telecommunication systems for rapid exchange of information, and highly trained personnel. This applies equally in most National Meteorological and Hydrological Centres including West African centres that have been extensively studied and presented by Tarhule et al. [6]. Among these tools, the following are included:

(1) Synergy Forecaster Workstation at National Meteorological Centre (NMC), which is used for data and product manipulation as well as visualization tools,

(2) African Monitoring of Environment for Sustainable Development (AMESD) Forecaster Workstation at NMC, which is used for data and product manipulation as well as visualization tools,

(3) African equipment for satellite data reception and dissemination at NMC,
TABLE 1: Meteorological and environmental stations in Kenya.

\begin{tabular}{|c|c|c|}
\hline Number of stations & Type of stations & Measurements taken \\
\hline 39 & $\begin{array}{l}\text { Synoptic surface } \\
\text { weather observation } \\
\text { stations }(24 / 7)\end{array}$ & $\begin{array}{l}\text { For horizontal } \\
\text { (spatial) atmospheric } \\
\text { sampling of weather } \\
\text { elements }\end{array}$ \\
\hline 1 & Upper air station & $\begin{array}{l}\text { For vertical } \\
\text { atmospheric sampling } \\
\text { of weather elements }\end{array}$ \\
\hline 17 & $\begin{array}{l}\text { Agrometeorological } \\
\text { stations }\end{array}$ & $\begin{array}{l}\text { For monitoring farm } \\
\text { crop conditions }\end{array}$ \\
\hline$>1000$ & Rainfall stations & $\begin{array}{l}\text { Dedicated to rainfall } \\
\text { measurements only }\end{array}$ \\
\hline 72 & $\begin{array}{l}\text { Automatic weather } \\
\text { stations (AWSs) }\end{array}$ & $\begin{array}{l}\text { For supplementing } \\
\text { conventional stations }\end{array}$ \\
\hline 3 & $\begin{array}{l}\text { Automatic weather } \\
\text { observing systems } \\
\text { (AWOS) }\end{array}$ & $\begin{array}{l}\text { For ensuring safety of } \\
\text { aircrafts at airports }\end{array}$ \\
\hline 17 & $\begin{array}{l}\text { HydroMet automatic } \\
\text { weather stations }\end{array}$ & $\begin{array}{l}\text { For monitoring } \\
\text { hydrological elements } \\
\text { for water resources } \\
\text { management }\end{array}$ \\
\hline 1 & $\begin{array}{l}\text { Global atmospheric } \\
\text { watch (GAW) } \\
\text { stations on } \\
\text { Mt. Kenya }\end{array}$ & $\begin{array}{l}\text { For background } \\
\text { pollution monitoring }\end{array}$ \\
\hline 2 & $\begin{array}{l}\text { Urban environmental } \\
\text { pollution monitoring } \\
\text { stations }\end{array}$ & $\begin{array}{l}\text { For pollution } \\
\text { monitoring }\end{array}$ \\
\hline 1 & $\begin{array}{l}\text { Ozonesonde station } \\
\text { (Dagoretti) }\end{array}$ & $\begin{array}{l}\text { For pollution } \\
\text { monitoring }\end{array}$ \\
\hline
\end{tabular}

(4) numerical weather prediction (NWP) that runs models such as consortium for small-scale modeling (COSMO) and weather research and forecasting model (WRF) of the US Weather Service, which provides a high performance computing platform for NWP, in which the models run 72-hour (or 3 days) forecast in less than 45 minutes with a resolution of $7 \mathrm{~km}$ for each,

(5) Computer PC Workstation for the National Climate Diagnostics Laboratory, for regional climate change scenario generation using the providing regional climates for impacts studies (PRECIS) model,

(6) automatic messaging switch center for telecommunication.

Most of the products of KMS are highly time sensitive and thus need to be disseminated to the users in the fastest modes possible. Faster communication of weather information has proved to be a major challenge to many weather organisations [15], although Kenya has developed a vibrant communication system [20]. The channels used in the dissemination of the meteorological products in KMS include press releases, interaction with media personnel, radio and TV channels, email services, government line ministries, website, and social media. At the county level where KMS has now decentralized its services, the information flow channels are 


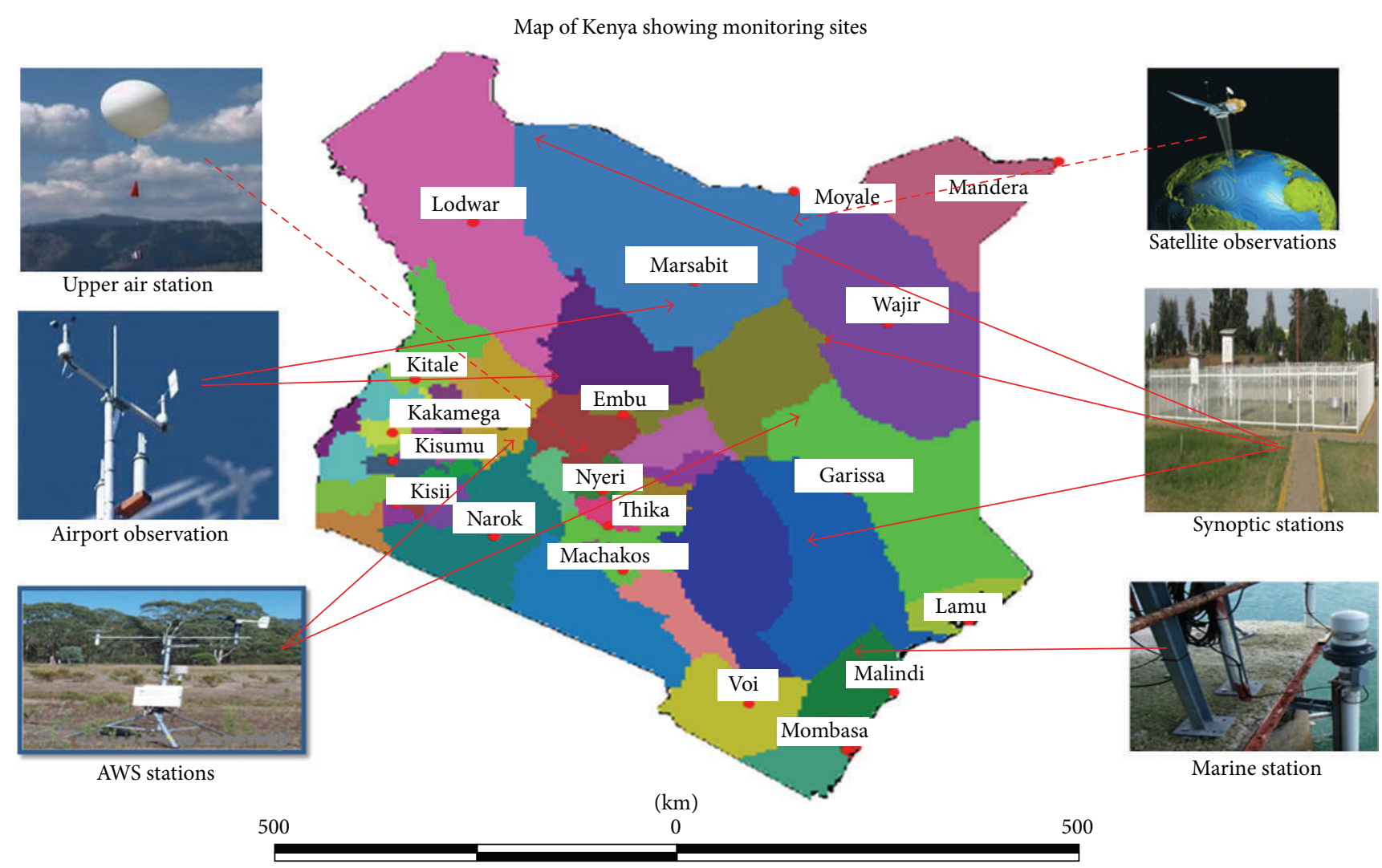

FIGURE 2: Kenya Meteorological Service observation stations pictorial depiction.

offices of the county directors of meteorology, radio, and Internet communications project (currently on air in Budalangi, Kangema, Suswa, and Kwale), Community Based Organizations, subcounty (district) development committee meetings, and chiefs' "barazas."

Different regions require different weather information $[3,16]$. KMS produces various forecasts and early warning products. They include historical and past climate records, real-time and near-real-time weather information, now casting for airport services, short-range weather forecasts, medium-range weather, long-range weather forecasts, and climate predictions. KMS also provides climate change information and severe weather advisories. This information helps in identifying suitable activities for specific areas and period to reduce weather related risks.

The critical concern is that there is inadequate observational network and poor spatial coverage. Some remote areas especially those located in semiarid and arid areas hardly have weather measuring/recording stations/equipment. Incidentally, these are the same areas, where weather information is of utmost importance for planning pastoral and agropastoral activities due to the high variability of the weather parameters in the region [3].

To ameliorate this, rehabilitation of the existing observational networks and installing new stations to ensure a dense network is encouraged. For the remote areas, automated stations are a good choice. KMS is in the process of expanding the network despite being at a slower pace. It also collaborates with other stakeholders with observational platforms such as remote sensing and other institutions. Again, KMS utilises the services of volunteer weather observers across the country.

New techniques are emerging as technology evolves. It is very difficult to provide location specific forecasts. KMS lacks modern facilities for data analysis and integration of products necessary to overlay various products for realization of more accurate forecasts [18]. There therefore is a need to improve and refine the weather models used and enhance the capacity in numerical weather prediction and dynamical modelling as well as the remote-sensing techniques. Ultimately, KMS should acquire modern facilities for data analysis and information presentation.

Again, there is limited clarity on what forecast formats are best suited to user needs although it is known that the optimal format may vary between applications. Use of information, once received, is not straightforward and if inappropriately used may lead to further difficulties. Production and delivery systems are somewhat fragmented and consequently it is sometimes difficult for forecasts to reach those end users who may have particular need for the information. End users often perceive a need for temporal and spatial detail (e.g., exact rainfall amounts, onset, and cession dates) in the prediction that currently cannot be achieved with much accuracy. Best method from the scientific perspective of delivering outlooks 


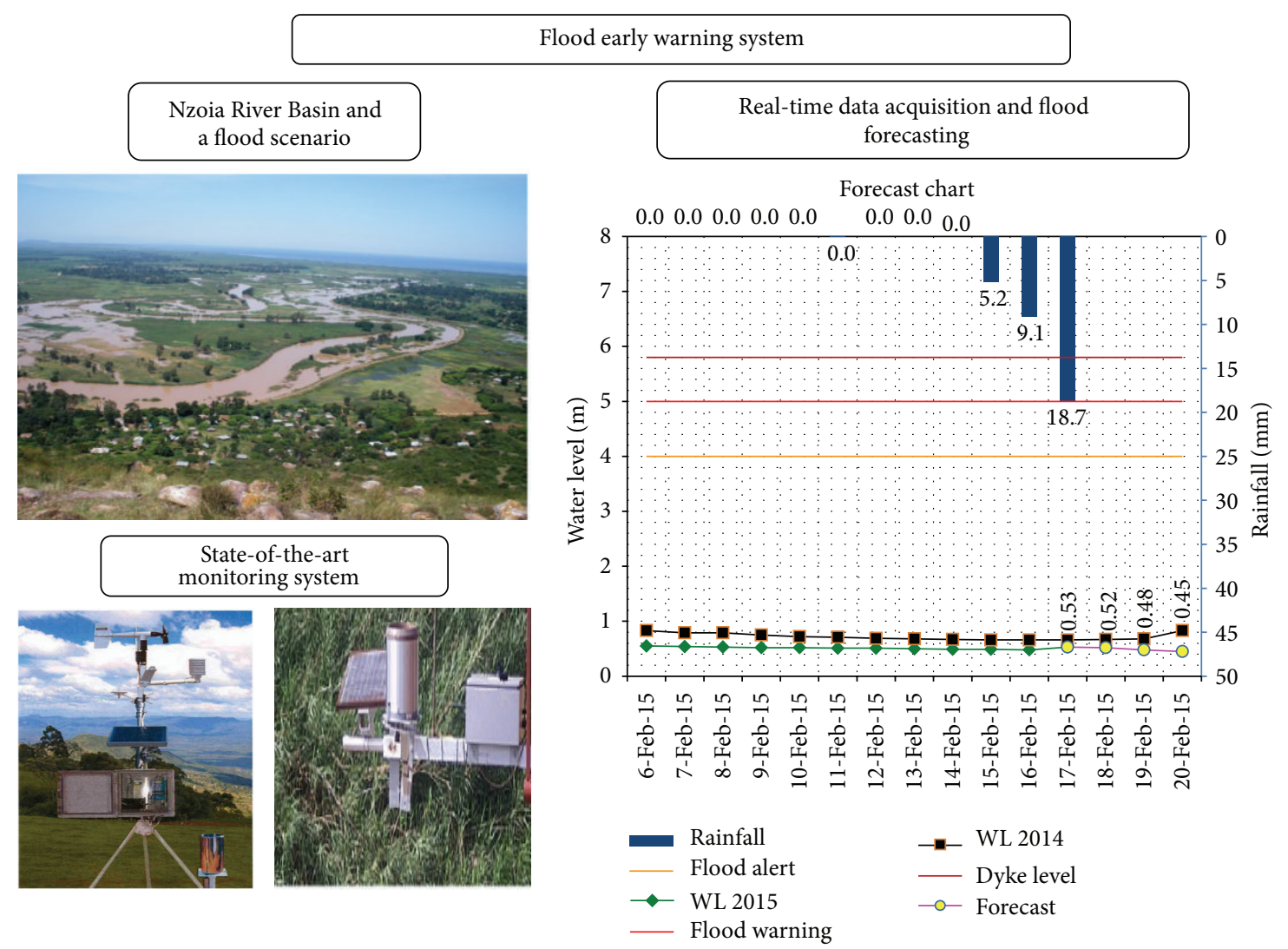

FIGURE 3: Sequence of flood early warning in Nzoia basin (source [13]).

is through probabilistic approaches. Probability forecasts, however, are often viewed as being difficult to understand and act upon [15].

To overcome this problem, meteorologists should consider linkages with end users of forecast information to develop user-oriented products, communicate the information in the user's local languages (particularly the pastoral communities), and develop techniques for raising the awareness of the user communities on the benefits of using weather information in decision-making. There is need for improvement of the modes of communication, for example, short messaging service (SMS) and common alerting protocol (CAP) [1]. Through collaborating with intermediaries, KMS is able to disseminate weather information services to county and subcounty levels using modern technology available, that is, SMS at reasonable speed and cost.

One of the problems in certain areas of Kenya is cyclic and perennial flooding during peak rainfall events of short heavy convective storms [10]. According to the early warning unit in the ministry of agriculture, flooding displaced over 20,000 people and destroyed close to 10,000 hectares of crops in the year 2003. Planning for risk reduction therefore requires an integrated flood management system. Kenya is divided into 5 main river basins, Nzoia, Tana River, Athi, and North and South Ewaso Nyiro. Most of the basins flood during seasonal rains causing destruction of property and loss of life [5]. KMS has attempted to address this problem in collaboration with other partners.

Although areas prone to flash floods are pointed out during media briefing on seasonal weather forecasts (reports available at http://www.meteo.go.ke/), KMS runs a successful flood monitoring and warning system in Nzoia Catchment through the Flood Diagnostics and Forecasting Centre. Nzoia River which runs through the catchment has a mean discharge rate of $118 \mathrm{~m}^{3} / \mathrm{s}$, but with highly variable flow ranging from $20 \mathrm{~m}^{3} / \mathrm{s}$ to $1100 \mathrm{~m}^{3} / \mathrm{s}$ [21]. The origin of Nzoia River, in the highlands of Cherangani, occasionally receives higher rainfall that controls the swelling of the river downstream, resulting in rising river levels with increased incidences of flooding in lower areas of Budalangi. KMS monitors both the flow of the river and the rain performance in the upper catchment with a view of noting some critical levels earlier predetermined to gauge possible flooding (Figure 3 ).

The monitoring is on real-time basis. Once the critical levels are reached, then either alerts or warnings are released [21]. Dissemination of the information is through the Budalangi community radio directly to local community members and local administrative officers [13]. Other ways of communications are utilised to pass the information to stakeholders such as emails and display the information on the web. Some of the gaps in flood warning programme are that there is inadequate hydrological and rainfall station 


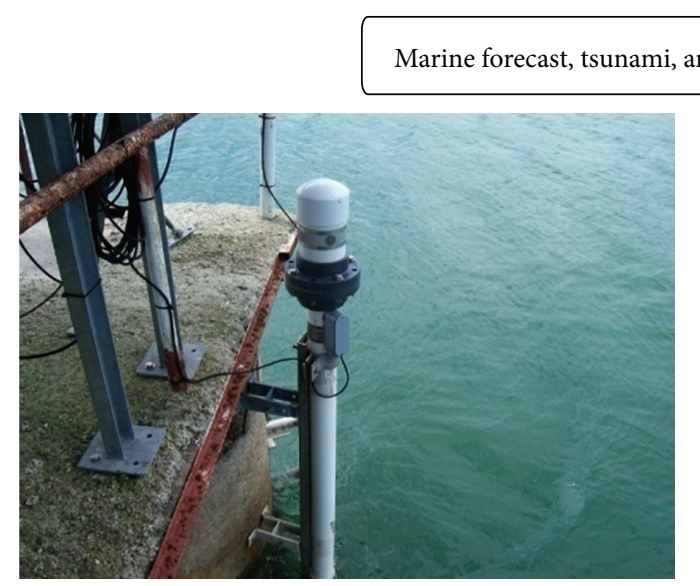

Tidal gauge at Shimoni, Kenya

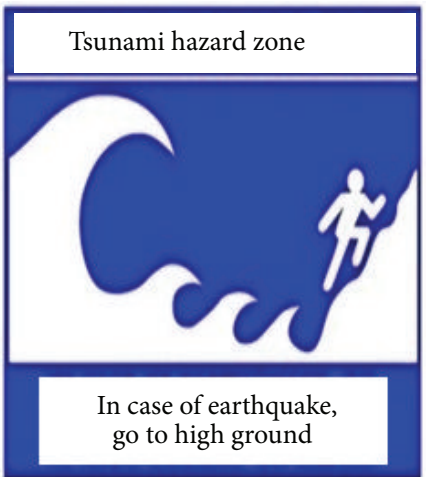

Tsunami information sign

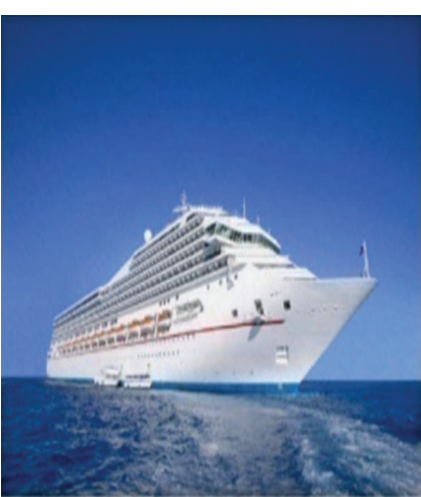

Cruise ship in fair weather

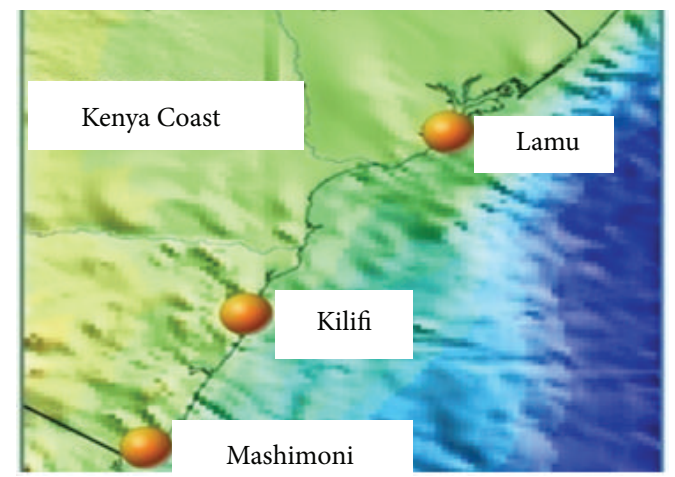

Tidal stations, Kenya Coast

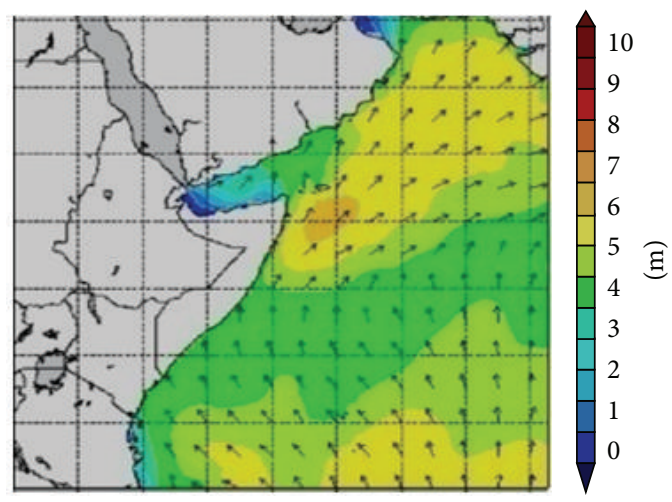

Marine forecast

FIGURE 4: Sequence of tsunami early warning in coastal Kenya (source [13]).

network within Nzoia basin. At times, there are telemetry problems of the observed data to headquarters due to delayed payment of bills and inadequate processing facilities.

Although tsunami is a geological phenomenon, it affects weather when there is an interaction between the atmosphere and the ocean through upwelling during tsunami waves. The Indian Ocean tsunami of December 2004 killed 220000 people and left 1.5 million homeless. In Kenya, a number of fishermen boats were destroyed in Malindi and Kilifi and one person died [13].

In response, the Government of Kenya designated the KMS as the National Tsunami Early Warning Centre, with the responsibility of monitoring tsunami activities in the Indian Ocean, while the National Disaster Operation Centre in the Ministry of State for Special Programmes was designated as the National Tsunami Information Centre, charged with the responsibility of coordinating response, relief, and rehabilitation [5]. The system is currently in place and the observational network has been enhanced (Figure 4). Moreover, the establishment of an early warning system using the tide stations will decrease the impact of tsunamis and other related maritime disasters (e.g., tropical cyclone, oil spills, marine accidents, store surges and strong ocean waves, etc.).

Modern technologies in ocean monitoring (Figure 4) and new developments in ocean-climate modelling require that the data be accurate and the system be durable to maximize the system's ability for early detection of tsunamis and weather [4]. Ocean modelling activities are coordinated through the KMS for the Western Indian Ocean Region [1]. The ocean observation platforms consist of instruments used for observation of sea level changes and for measurement of meteorological and oceanographic parameters like sea surface temperature and ocean currents.

KMS has come up with a comprehensive plan of establishing a seismic and tide gauge network. Three tidal gauges have already been installed while acquisition of broadband seismometers is underway. In the pipeline is installation of sirens and public address systems along the coastal region. It is envisaged that Kenya tsunami hazard maps and escape routes will be developed [13]. Since the task is enormous, Kenya has encouraged development partners like Japan International Development Agency to join hand in achieving this noble objective. The department is therefore expected in the very near future to effectively issue warnings related to tsunami and earthquake in order to mitigate their effects.

A malaria epidemic prediction model has been developed using thresholds of monthly maximum temperature anomalies and minimum mean monthly rainfall by Kenya Medical Research Institute [22]. The model is able to detect meteorological risk factors that would precipitate an epidemic 3-4 

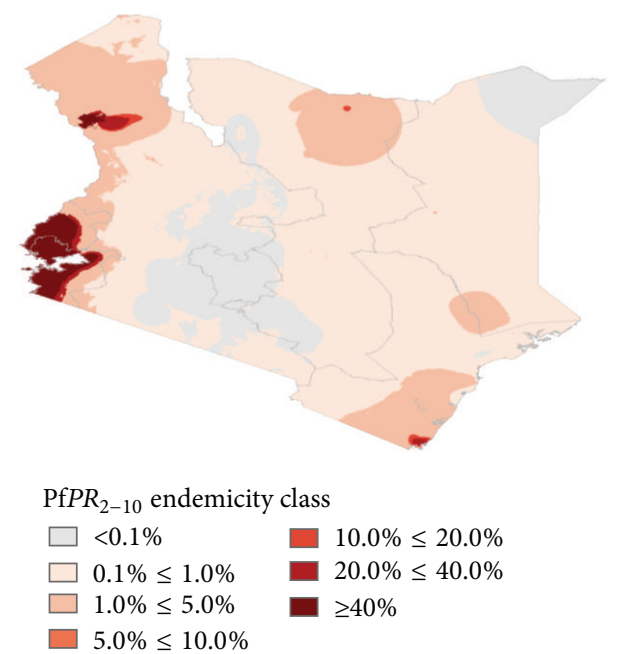

FIgURE 5: Spatial distribution malaria in Kenya in 2009 based on geospatial modelling (source [23]).

months before the onset. Once the risk of outbreak has been identified, advice is then provided to the target population on what intervention measures to undertake, such as protecting themselves, use of vaccines, drugs, insecticides, and bed nets that can only be organized by health agencies or institutions. Thus, the model picture is complex to arrive at. The difficulty lies in determining which factors are most responsible for influencing the distribution and intensity of the disease. A study by Noor et al., [23] using geostatistical modelling, developed a national map of malaria's risk distribution in Kenya for 2009 (Figure 5).

\section{Conclusion}

KMS has a series of activities geared towards weather early warning. The link between weather institutions and policy decision takers both in government and in NGOs with the local communities strengthens access to weather information. For the information to be beneficial, it is paramount that the early warning in KMS be strengthened and improved. Building credible weather data inventories and identifying and continuously monitoring both the risk indicators, for example, rainfall, temperature, and the vulnerable local residents, are prerequisites for successful early warning.

\section{Recommendations}

The research recommends that weather forecasts be devolved to the counties in developing strong early warning. It further recommends that language and communication of the weather information be improved in temporal and spatial scales with the use of new and emerging technology. KMS should enhance its efforts in awareness creation and public understanding of weather services. This leads to increased uptake and confidence in applying the weather knowledge in alleviating risks on societies. Partnerships between public and private sectors are enhanced by sharing lessons learnt and efforts being made to mitigate weather related hazards.

Specialized early warning plan of actions such as Kenya's National Adaptation Plan of Action [5] should formulate development approaches in climate impact assessment needs for each region in Kenya focusing on their uniqueness and hence different plans. Finally, it is the responsibility of all, the government, international and local NGOs, and the local communities, to develop early warning.

\section{Conflict of Interests}

The authors declare that there is no conflict of interests regarding the publication of this paper.

\section{Acknowledgment}

The authors wish to acknowledge the assistance from Kenya Meteorological Service.

\section{References}

[1] WMO, Reducing and Managing Risks of Disasters in a Changing Climate, vol. 62, (Special Issue), World Meteorological Organisation, Geneva, Switzerland, 2013.

[2] IPCC, "Summary for policymakers," in Climate Change 2013: The Physical Science Basis. Contribution of Working Group I to the Fifth Assessment Report of the Intergovernmental Panel on Climate Change, T. F. Stocker, D. Qin, G. K. Plattner et al., Eds., Cambridge University Press, Cambridge, UK, 2013.

[3] Drought Monitoring Centre (DMC), Factoring of Weather and Climate Information and Products into Disaster Management Policy for Kenya: A Contribution for Disaster Strategies for Kenya, IGAD Climate Prediction Centre, Nairobi, Kenya, 2002.

[4] UNEP, Early Warning Systems: A State of the Art Analysis and Future Directions, Division of Early Warning and Assessment (DEWA), United Nations Environment Programme (UNEP), Nairobi, Kenya, 2012.

[5] Government of Kenya, National Climate Change Action Plan, 2013-2017, Executive Summary, Ministry of Environment Water and Natural Resources, Nairobi, Kenya, 2013.

[6] A. Tarhule, Z. Saley-Bana, and P. J. Lamb, "Rainwatch: a prototype GIS for rainfall monitoring in West Africa," Bulletin of the American Meteorological Society, vol. 90, no. 11, pp. 16071614, 2009.

[7] R. S. Pulwarty and M. V. K. Sivakumar, "Information systems in a changing climate: early warnings and drought risk management," Weather and Climate Extremes, vol. 3, pp. 14-21, 2014.

[8] C. Funk, G. Eilerts, F. Davenport, and J. Michaelsen, "A climate trend analysis of Kenya-August 2010," US Geological Survey Fact Sheet 3074, 2010.

[9] Government of Kenya, The Constitution of Kenya, 2010, Government Printing Press, Nairobi, Kenya, 2010.

[10] J. H. Bowden and F. H. M. Semazzi, "Empirical analysis of intraseasonal climate variability over the Greater Horn of Africa," Journal of Climate, vol. 20, no. 23, pp. 5715-5731, 2007.

[11] M. I. Lélé and P. J. Lamb, "Variability of the Intertropical Front (ITF) and rainfall over the West African Sudan-Sahel zone," Journal of Climate, vol. 23, no. 14, pp. 3984-4004, 2010. 
[12] D. Conway, "Adapting climate research for development in Africa," Wiley Interdisciplinary Reviews: Climate Change, vol. 2, no. 3, pp. 428-450, 2011.

[13] Government of Kenya, National Climate Change Response Strategy, Ministry of Environment Water and Natural Resources, Nairobi, Kenya, 2010.

[14] IPCC, "Summary for policymakers," in Managing the Risks of Extreme Events and Disasters to Advance Climate Change Adaptation, C. B. Field, V. Barros, T. F. Stocker et al., Eds., A Special Report of Working Groups I and II of the Intergovernmental Panel on Climate Change, pp. 1-19, Cambridge University Press, Cambridge, UK, 2012.

[15] D. Melain, C. Kate, R. Cornforth et al., Integrating Science into Humanitarian and Development Planning and Practice to Enhance Community Resilience, University College London, London, UK, 2014.

[16] P. Cooper, R. Stern, M. Noguer, and J. Gathenya, "Climate change adaptation strategies in Sub-Saharan Africa: foundations for the future," in Climate Change-Realities, Impacts Over Ice Cap, Sea Level and Risks, B. R. Singh, Ed., InTech, 2013.

[17] UNISDR, Global Survey of Early Warning Systems, United Nations International Strategy for Disaster Reduction, Geneva, Switzerland, 2006.

[18] A. Tarhule and P. J. Lamb, "Climate research and seasonal forecasting for West Africans: perceptions, dissemination, and use?" Bulletin of the American Meteorological Society, vol. 84, no. 12, pp. 1741-1759, 2003.

[19] C. Roncoli, K. Ingram, and P. Kirshen, "The costs and risks of coping with drought: livelihood impacts and farmers' responses in Burkina Faso," Climate Research, vol. 19, no. 2, pp. 119-132, 2001.

[20] L. Ogallo, "The mainstreaming of climate change and variability information into planning and policy development for Africa," Procedia Environmental Sciences, vol. 1, pp. 405-410, 2010.

[21] J. Hoedjes, A. Kooiman, B. Maathuis et al., "A conceptual flash flood early warning system for Africa, based on terrestrial microwave links and flash flood guidance," ISPRS International Journal of Geo-Information, vol. 3, no. 2, pp. 584-598, 2014.

[22] A. K. Githeko, S. W. Lindsay, U. E. Confalonieri, and J. A. Patz, "Climate change and vector-borne diseases: a regional analysis," Bulletin of the World Health Organization, vol. 78, no. 9, pp. 1136-1147, 2000.

[23] A. M. Noor, P. W. Gething, V. A. Alegana et al., "The risks of malaria infection in Kenya in 2009," BMC Infectious Diseases, vol. 9, article 180, 2009. 

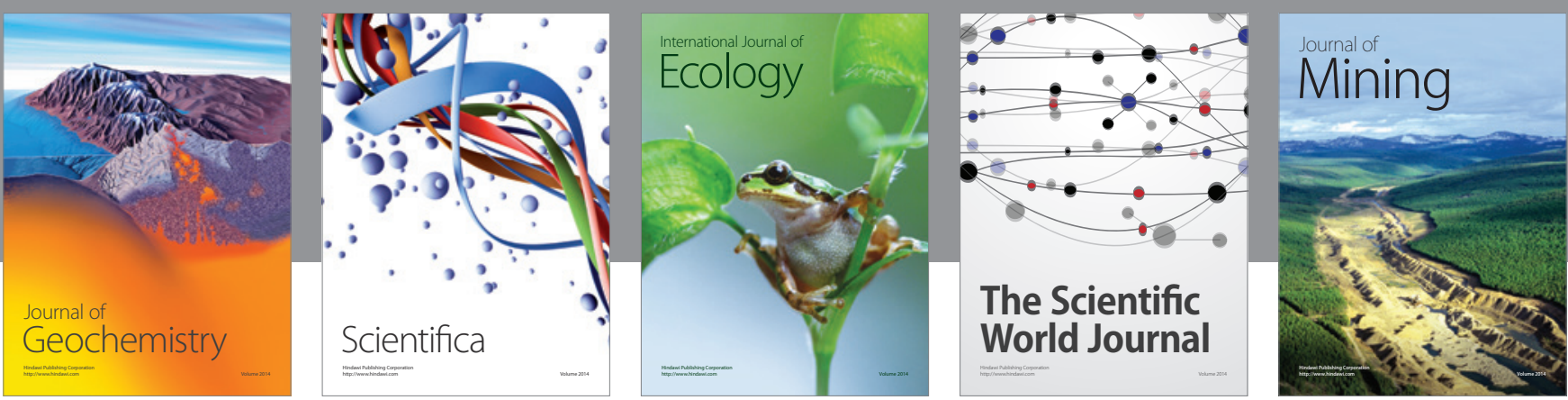

The Scientific World Journal
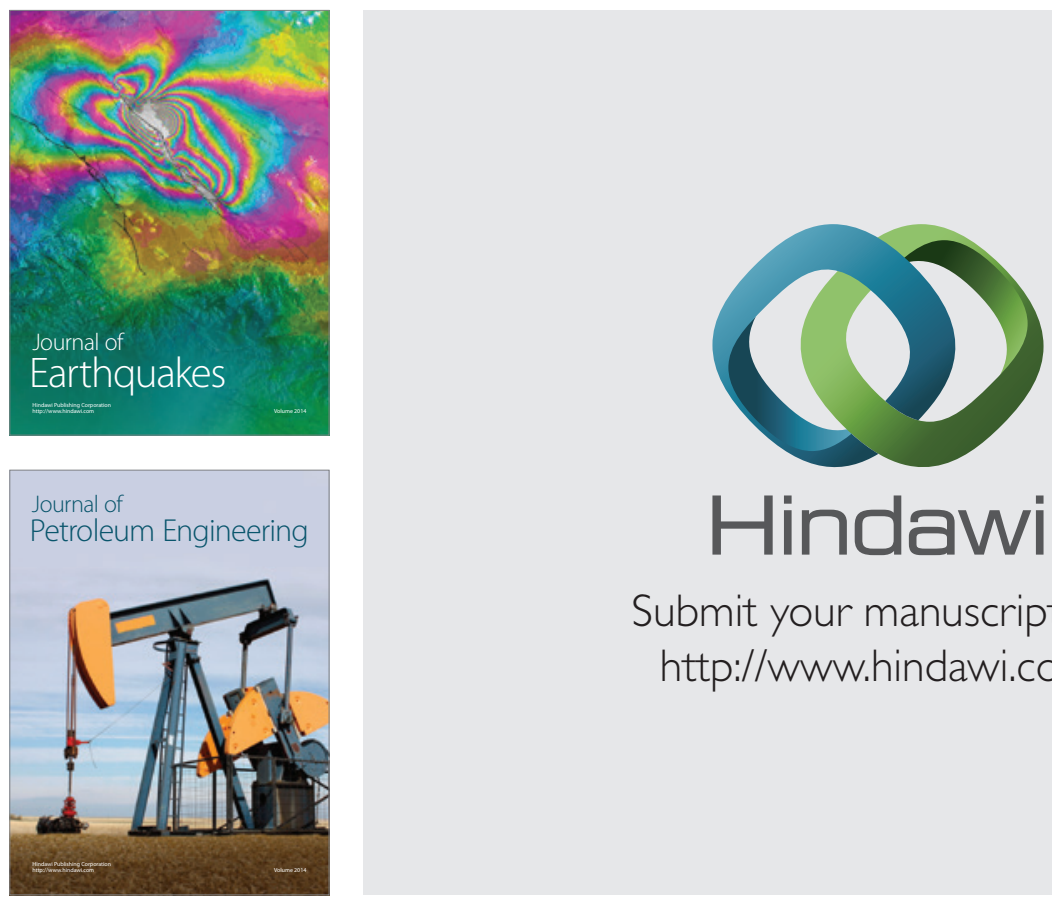

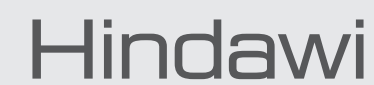

Submit your manuscripts at

http://www.hindawi.com
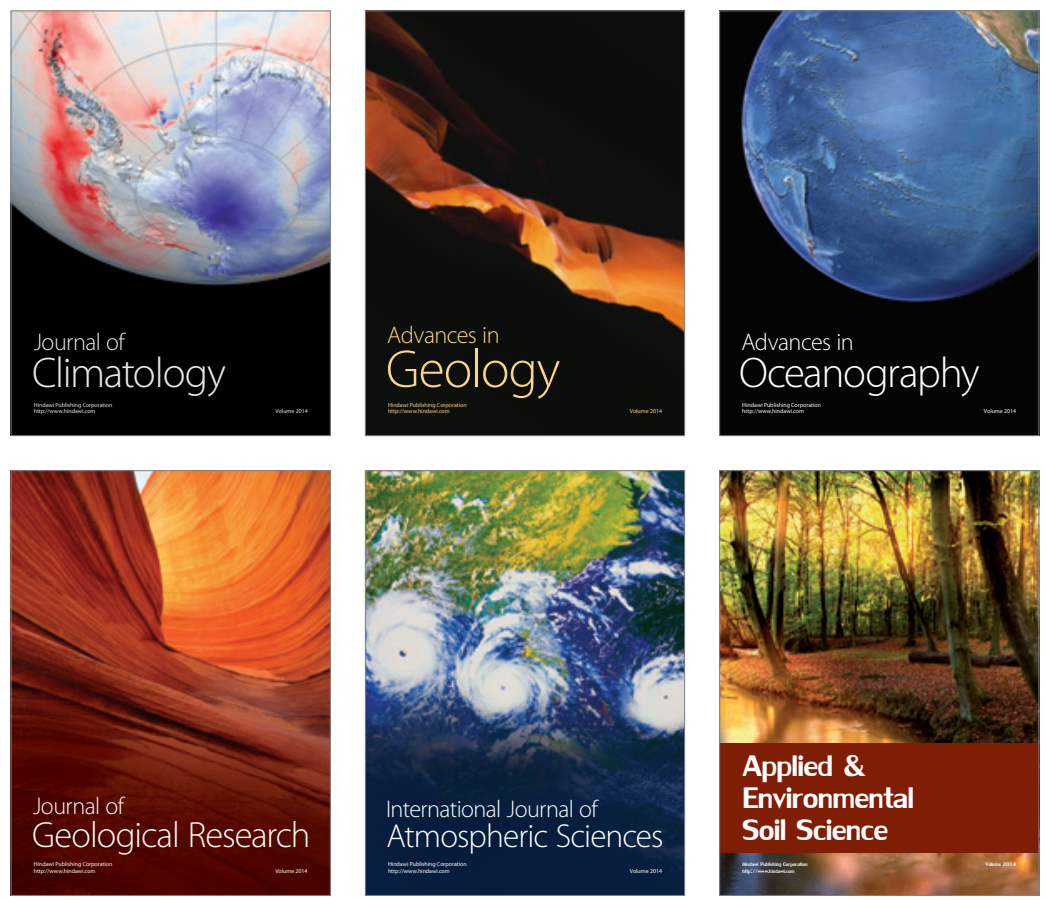
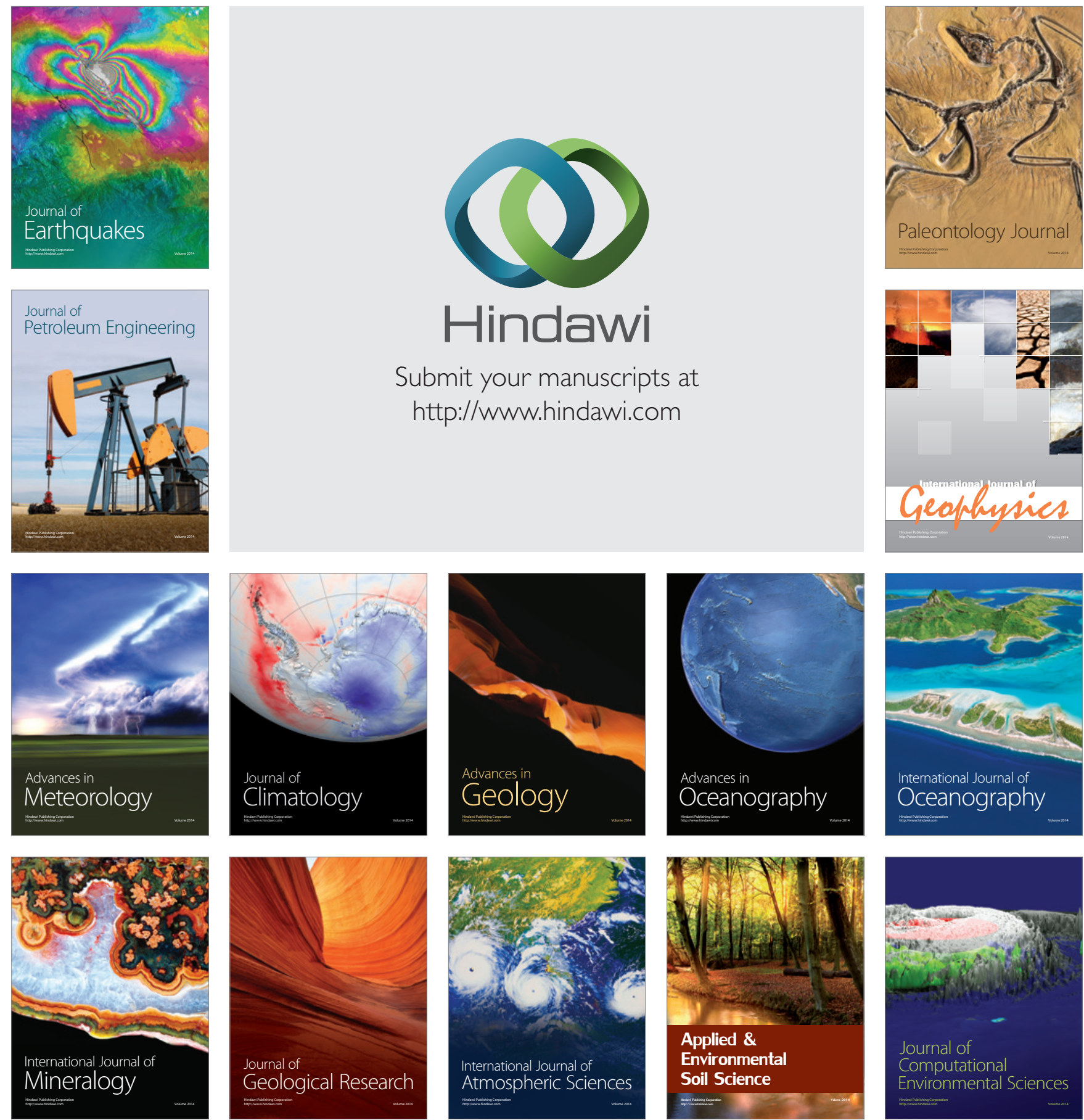